\title{
Effect of Inhibitors on the Morphology and Growth of Allomyces macrogynus
}

\author{
By DANIEL D. BURKE AND MARILYN GERMOND \\ Department of Microbiology, University of Illinois, Urbana, Illinois 6I80 I, U.S.A.
}

(Received 21 March 1975 ; revised 7 November 1975)

SUMMAR Y

The ability of 18 compounds to inhibit morphogenesis and/or growth of the diploid stage of Allomyces macrogynus was assayed. Of the three stages of development-germination, vegetative growth, and sporogenesis-germination appeared to be the most sensitive to inhibition and vegetative growth the least sensitive. Sporogenesis was sensitive to most of the inhibitors tested, but high concentrations were required for effective activity. Inhibitors could be grouped according to the stage of germination (cyst or rhizoid) at which they blocked development; those effective at the rhizoid stage, could be divided further on the basis of the resultant morphology of the germling.

\section{INTRODUCTION}

The phycomycete Allomyces macrogynus is well-suited for developmental studies of eukaryotic organisms. During its diploid life-cycle (spore germination, vegetative growth, and sporogenesis) it produces a number of well-defined, differentiated cell types (Lovett, I967; Burke, Seale \& McCarthy, I972). The life-cycle can be conveniently reproduced on defined medium and large amounts of the cell types can be obtained by manipulation of growth conditions (Emerson \& Wilson, 1954; Machlis \& Crasemann, 1956; Machlis et al., I966).

This report examines the effect of inhibitors, known to have specific biochemical effects in other eukaryotic systems, on the morphogenesis and growth of the diploid life-cycle of A. macrogynus. Differential effects of inhibitors on morphogenesis and growth may allow the development of tools for examining specific events in the life-cycle. An extensive survey has been made of the effects of inhibitors on several phycomycetes, including A. macrogynus (Matsuma \& Cantino, r97I). However, only the inhibition of the overall process of germination was measured: neither the stage of germination affected, nor the inhibitory effects on vegetative growth or sporogenesis were determined.

Several qualitative measurements of inhibition in phycomycetes have been reported. Cycloheximide blocks germination at the cyst stage in $A$. arbuscula (Burke et al., 1972) and Blastocladiella emersonii (Lovett, 1968); and actinomycin D blocks germination at the rhizoid stage in both of these organisms. Actinomycin D blocks sporogenesis in Achlya ambisexualis (Griffin \& Breuker, 1969), but not in A. arbuscula (Burke et al., 1972) and B. emersonii (Murphy \& Lovett, 1966).

\section{METHODS}

Strain. All studies were performed with the sporophyte stage of Allomyces macrogynus Burma. 
Growth and inhibition studies. In studies of the effects of inhibitors on either germination or vegetative growth, mitospores, at a final concentration of $5 \times 10^{4} \mathrm{ml}^{-1}$, were inoculated in $25 \mathrm{ml}$ of Machlis minimal medium (Machlis, I953) modified by the addition of glutamic acid $\left(500 \mu \mathrm{g} \mathrm{ml}^{-1}\right)$. The inclusion of glutamic acid greatly enhanced growth and increased the maximum mass reached by the culture. The mitospores were obtained as described previously (Burke et al., 1972). In germination experiments, inhibitors were present in the medium at the time of spore inoculation; in vegetative growth experiments, inhibitors were added after either 16 or $24 \mathrm{~h}$ growth. All cultures were incubated at $28{ }^{\circ} \mathrm{C}$ in a rotary-shaking water bath operating at $125 \mathrm{rev}$./min. Spore induction was accomplished by filtering $16 \mathrm{~h}$ cultures on a stainless-steel mesh and then resuspending in 'dilute salt' solution (Machlis \& Crasemann, 1956). Inhibitors were present from the time of spore induction, which was monitored visually for $6 \mathrm{~h}$.

Measurement of inhibition. Inhibition was determined by: (i) following the interference in the normal morphological development of cultures during germination and sporangium induction; and (ii) measuring the dry weight of the culture. In all cases duplicate test cultures were weighed after $24 \mathrm{~h}$ drying at $60^{\circ} \mathrm{C}$, and inhibition was measured at least twice.

Inhibitors. Mitomycin C, emetine hydrochloride, chloramphenicol, tetracycline, 2,4dinitrophenol (2,4-DNP), fluorouracil, $p$-fluorophenylalanine, and azaguanine were ob tained from Sigma; acridine orange from Polysciences, Inc.; nalidixic acid, ethidium bromide, actinomycin $\mathrm{D}$, rifampin, cycloheximide, puromycin, neomycin, and polymyxin from Calbiochem; and sodium azide from Eastman.

Light microscopy. A Leitz photomicroscope was employed for all observations. Wet mounts were made on glass slides. In some cases the slides were coated with $2 \%(w / v)$ agar.

\section{RESULTS}

\section{Effect of inhibitors on growth of spores}

Eighteen compounds were tested for their ability to inhibit the growth of A. macrogynus in cultures started from mitospores. They included compounds which have been shown to inhibit DNA synthesis, RNA synthesis, protein synthesis, membrane synthesis, and mitochondrial function in eukaryotic systems.

Most of the test compounds inhibited growth, as measured by dry weight increase, by at least $50 \%$ at a concentration of $20 \mu \mathrm{g} \mathrm{ml}^{-1}$ or less; although some required up to $55 \mu \mathrm{g}$ $\mathrm{ml}^{-1}$ for $50 \%$ inhibition and $200 \mu \mathrm{g} \mathrm{ml}^{-1}$ for $90 \%$ inhibition (Fig. I, Table I). There did not appear to be any relationship between the amount of inhibitor necessary and the probable function inhibited. For most compounds, a concentration of two to three times that producing $50 \%$ inhibition yielded at least $90 \%$ inhibition. A plot of the percentage inhibition versus the $\log$ of the dose generally gave a straight line, suggesting a zero order interaction, which may be indicative of a unique site for inhibitor sensitivity. The few exceptions to this relationship occurred at the highest levels of inhibition (over $90 \%$ ) where measurements were most difficult to make. There was a wide variation in sensitivity to different inhibitors.

\section{Effect of inhibition on vegetative growth}

In the above experiments, inhibition was measured by determining the dry weight of the cultures relative to the dry weight of an untreated control. Since inhibitors were present prior to germination and measurements were not made until the control culture reached its maximum vegetative growth, it was possible that we were measuring inhibition of vegetative growth rather than inhibition of germination. However, cultures inhibited by $90 \%$ 


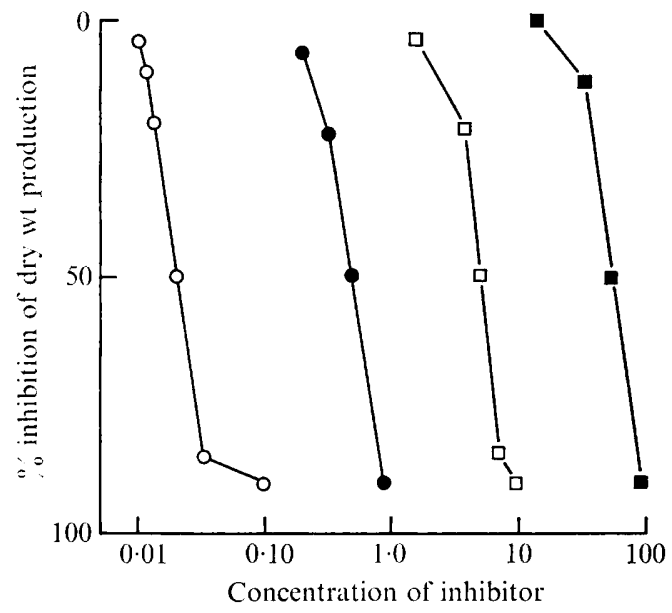

Fig. I. Inhibition of growth by various inhibitors. Cultures were started from spores as detailed in Methods. The percentage inhibition of dry weight production of the culture relative to an untreated control after $40 \mathrm{~h}$ incubation is plotted versus the concentration of inhibitor. $\mathrm{O}$, Cycloheximide;, fluorouracil; $\square$, fluorophenylalanine; $\mathbf{\square}$, rifampin.

\section{Table I. The effective concentrations of inhibitors of growth and of sporangium formation} in A. macrogynus, and the stage of germination that the inhibitors affected

For determination of growth inhibition, cultures were started from mitospores and grown for $40 \mathrm{~h}$ as detailed in Methods: inhibitors were present at the time of inoculation. Results are expressed as the inhibitor concentration required to inhibit the increase in the dry weight of the culture relative to that of an untreated control by $50 \%$ or $90 \%$. The stage at which germination was affected (cyst or rhizoid) was determined visually.

For inhibition of sporangium formation, results are expressed as the minimum concentration necessary to block sporangium formation.

\begin{tabular}{|c|c|c|c|c|}
\hline \multirow[b]{2}{*}{ Inhibitor } & \multicolumn{2}{|c|}{$\begin{array}{l}\text { Concn }\left(\mu \mathrm{g} \mathrm{ml}^{-1}\right) \text { for } \\
\text { growth inhibition: }\end{array}$} & \multirow{2}{*}{$\begin{array}{c}\text { Germination } \\
\text { stage } \\
\text { blocked* }\end{array}$} & \multirow{2}{*}{$\begin{array}{c}\text { Concn }\left(\mu \mathrm{g} \mathrm{ml}^{-1}\right) \\
\text { for sporangium } \\
\text { formation } \\
\text { inhibition } \dagger\end{array}$} \\
\hline & $50 \%$ & $90 \%$ & & \\
\hline Cycloheximide & 0.02 & 0.1 & C & $I \cdot O$ \\
\hline Fluorouracil & 0.5 & 0.9 & $\mathbf{R}$ & IOO.O(NE) \\
\hline Ethidium bromide & $I \cdot I$ & $2 \cdot 5$ & $\mathbf{R}$ & 50.0 \\
\hline Sodium azide & $I \cdot 5$ & $20 \cdot 0$ & C & $100 \cdot 0$ \\
\hline 2,4 -DNP & $1 \cdot 5$ & 16.5 & $\mathrm{C}$ & $25 \cdot 0$ \\
\hline Tetracycline & $2 \cdot 0$ & $38 \cdot 0$ & $\mathbf{R}$ & $500 \cdot 0$ \\
\hline Azaguanine & $2 \cdot 5$ & $7 \cdot 0$ & $\mathbf{R}$ & $25 \cdot 0$ \\
\hline Actinomycin D & $2 \cdot 5$ & $5 \cdot 0$ & $\mathbf{R}$ & $10 \cdot 0$ \\
\hline Fluorophenylalanine & 5.0 & $9 \cdot 5$ & $\mathbf{R}$ & $\mathrm{IOO} \cdot \mathrm{O}(\mathrm{NE})$ \\
\hline Mitomycin C & $6 \cdot 0$ & $12 \cdot 0$ & $\mathbf{R}$ & $100 \cdot 0(\mathrm{NE})$ \\
\hline Chloramphenicol & $9 \cdot 0$ & $40 \cdot 0$ & $\mathbf{R}$ & $500 \cdot 0(\mathrm{NE})$ \\
\hline Emetine-HCl & $9 \cdot 5$ & $16 \cdot 0$ & $\mathbf{R}$ & $20 \cdot 0$ \\
\hline Polymyxin & II 0 & $15 \cdot 0$ & $\mathbf{R}$ & $25 \cdot 0$ \\
\hline Nalidixic acid & 15.0 & 25.0 & $\mathbf{R}$ & $50 \cdot 0(\mathrm{NE})$ \\
\hline Neomycin & $20 \cdot 0$ & $200 \cdot 0$ & $\mathbf{R}$ & 100.0 \\
\hline Puromycin & $20 \cdot 0$ & $50 \cdot 0$ & $\mathbf{R}$ & $50 \cdot 0$ \\
\hline Acridine orange & $23 \cdot 0$ & $75 \cdot 0$ & $\mathbf{R}$ & IOO.O(NE) \\
\hline Rifampin & $55^{\circ} 0$ & $95^{\circ} 0$ & $\mathbf{R}$ & $500 \cdot 0$ \\
\hline
\end{tabular}

${ }^{*} \mathrm{C}$, Cyst; $\mathrm{R}$, rhizoid. $\uparrow \mathrm{NE}$, Inhibitor had no effect at this concentration. 

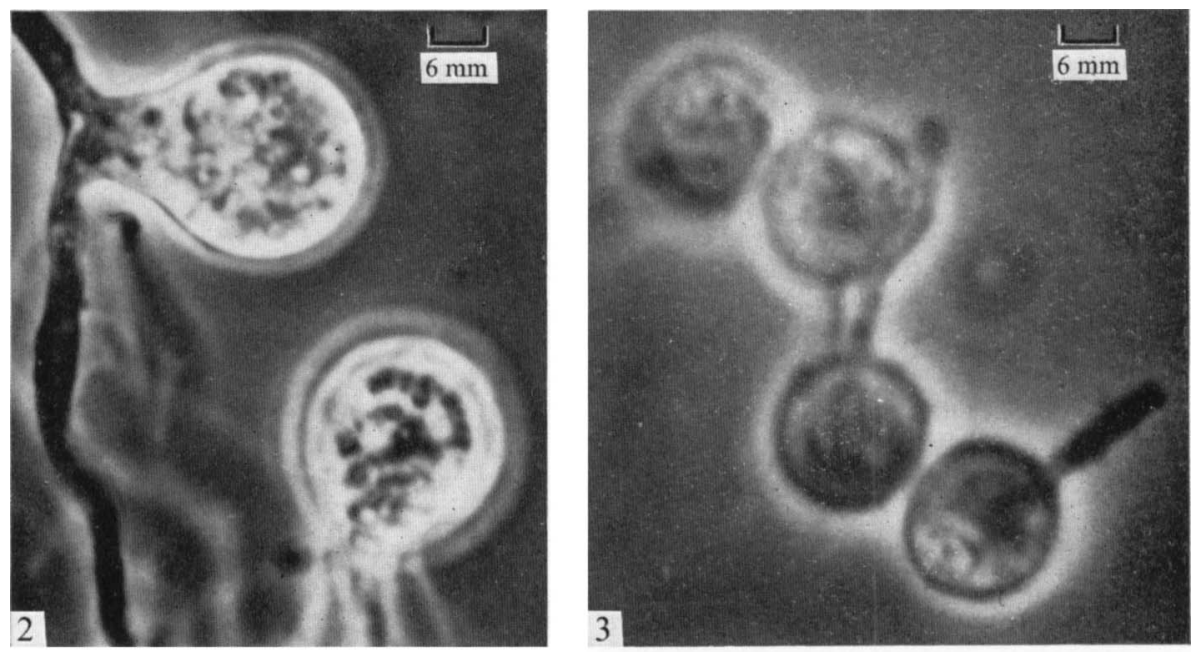

Fig. 2. Inhibition by fluorophenylalanine. Spores germinated in the presence of fluorophenylalanine $\left(50 \mu \mathrm{g} \mathrm{ml}^{-1}\right)$ after $40 \mathrm{~h}$ incubation. Bar marker represents $20 \mu \mathrm{m}$.

Fig. 3. Inhibition by ethidium bromide. Spores germinated in the presence of ethidium bromide $\left(5^{\circ} 0 \mu \mathrm{g} \mathrm{ml}^{-1}\right)$ after $40 \mathrm{~h}$ incubation. Bar marker represents $50 \mu \mathrm{m}$.

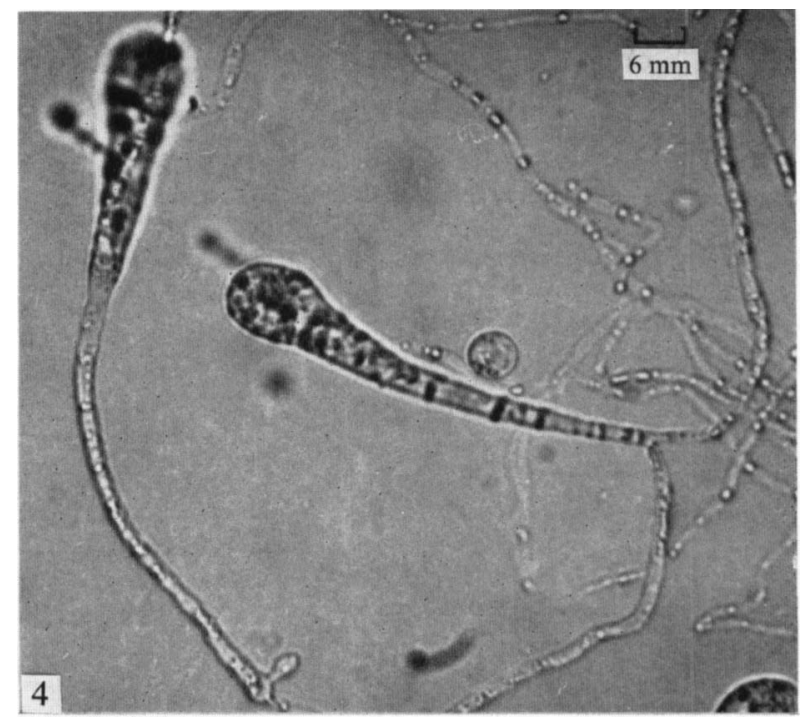

Fig. 4. Inhibition by chloramphenicol. Spores germinated in the presence of chloramphenicol ( $100 \mu \mathrm{g} \mathrm{ml}^{-1}$ ) after $40 \mathrm{~h}$ incubation. Bar marker represents $50 \mu \mathrm{m}$.

or more were always in the germling stage, and those inhibited to a lesser extent were a mixture of germlings and vegetative growth of normal appearance: thus, the primary effect of inhibition appears to be on germination. When the compounds, at concentrations which caused $90 \%$ inhibition in cultures started from mitospores, were added to cultures after I $6 \mathrm{~h}$ growth, they had no effect on the dry weight increase of cultures relative to that of an untreated control. To measure the effect of inhibitors on vegetative growth, they were added after $24 \mathrm{~h}$ growth to untreated cultures and the dry weights of these cultures were measured 
after another $8 \mathrm{~h}$ growth. During this time, the dry weight of the controls increased at maximum rate. Only rifampin, $p$-fluorophenylalanine and 2,4-DNP caused any significant inhibition of weight increase; all other compounds either did not inhibit the dry weight increase, or apparently stimulated it. Vegetative growth appeared to be much less sensitive to inhibition than germination since the three compounds giving significant inhibition were present at concentrations three to five times greater than those required for $90 \%$ inhibition of growth when starting from spores (Table I).

\section{Effect of inhibition on morphology during germination}

The specific morphogenetic event during germination which was most severely affected by each test compound was determined by visual observation of the treated cultures. Typically, spore germination consists of four stages: mitospore, cyst formation, rhizoid outgrowth, and hyphal formation. The inhibitors tested fell into two classes when considering their maximum effect upon germination: there was either no.development beyond cyst formation or no development beyond rhizoid formation (Table I).

High concentrations of cycloheximide, sodium azide, and 2,4-DNP, inhibited germination at the cyst stage; all other compounds inhibited germination at the rhizoid stage.

There were, however, significant differences in the appearance of the organisms blocked at the rhizoid stage. The addition of $p$-fluorophenylalanine and fluorouracil produced organisms that appeared to have several rhizoid roots rather than the normal single root (Fig. 2). Ethidium bromide inhibition gave rise to spherical cells with a straight, unbranched rhizoid - a 'lollipop' shape (Fig. 3), which is typical of the initial morphology of the normal rhizoid stage. In other cases, there seemed to be a definite elongation and thickening of the base of the rhizoid prior to cessation of growth (Fig. 4). Thus, although the majority of these inhibitors blocked development at the rhizoid stage, they exhibited a differential effect on the morphology of the inhibited germling. The examples shown in Figs. 2, 3 and 4 represent the majority of the population present and are not isolated instances.

\section{Effect of inhibitors on sporogenesis}

Many of the inhibitors were also able to block sporogenesis (Table I). The concentrations necessary for effective inhibition were not always the same as those effective during germination. Some inhibitors, such as ethidium bromide, tetracycline and sodium azide, were only effective at considerably greater concentrations than those effective in blocking germination; actinomycin D, 2,4-DNP, and polymyxin were effective at concentrations similar to those blocking germination, whereas other inhibitors, such as fluorouracil, $p$-fluorophenylalanine, and mitomycin were not effective at the concentrations tested. Those inhibitors which were effective did not demonstrate any differential effect: all blocked the appearance of the first stage of sporogenesis.

\section{DISCUSSION}

Our studies have shown that germination of $A$. macrogynus mitospores is differentially susceptible to a number of inhibitors of known functions in other eukaryotic systems. Vegetative growth and sporogenesis were also sensitive to some of the inhibitors, but required much higher levels for inhibition to occur and did not display any differential inhibitory response.

None of the inhibitors stopped the encystment process. Apparently the cell-wall synthesis necessary for encystment does not require any function blocked by the inhibitors. 
It has been previously demonstrated (Burke et al., 1972) that cytoplasmic protein synthesis is required for differentiation from cyst to rhizoid. Cycloheximide, an inhibitor of cytoplasmic protein synthesis (Pestka, I971), and 2,4-DNP and sodium azide (Harold, 1972), uncouplers of oxidative phosphorylation, inhibited growth beyond the cyst stage. However, inhibitors of protein synthesis, emetine and puromycin (Pestka, I97I), and $p$-fluorophenylalanine, a phenylalanine analogue, did not block the transformation of cyst to rhizoid, even at concentrations that were five to ten times higher than those resulting in $90 \%$ inhibition of growth. Our experiments did not explain why these latter inhibitors of protein synthesis did not block germination at encystment.

Ethidium bromide and other inhibitors of mitochondrial function, i.e. nalidixic acid, rifampin, chloramphenicol, tetracycline, and neomycin (Kroon \& DeVries, 1970), blocked germination at the rhizoid stage. It seems likely that mitochondrial function is required for growth beyond germination. Ethidium bromide inhibition was of further interest since it appeared to partition the germination process by inhibiting the dispersal of the nuclear cap. This structure, which contains all of the spore ribosomes, breaks down at encystment, dispersing the ribosomes throughout the cell (Lovett, 1963). In the presence of ethidium bromide many of the germlings had intact nuclear caps even when the rhizoid was present.

It is apparent that dry weight measurements cannot be used as an indicator of the inhibition of vegetative growth. While we were able to measure an effect on vegetative growth, the treated organisms actually weighed more than the controls in some cases, thus precluding a true measurement of inhibition. One possible explanation is that inhibition of growth stimulates accumulation of storage polymers such as glycogen or polyphosphate, and it is these materials that cause the weight increase. Other studies have shown that the organism does contain a hexose phosphate polymer which could be a candidate for this material (unpublished results).

Dry weight measurement, however, did seem to be a reliable indicator of inhibition, at least at greater than $90 \%$ inhibition, in cultures started from mitospores. This was indicated by the observation that these cultures were all in the germination stage. Further, we have made some measurements of the DNA content of inhibited cultures relative to control cultures and have found that inhibition of dry weight and DNA content are similar ( $\pm 10 \%)$ in the range of 30 to $80 \%$ inhibition. The percentage of DNA per unit dry weight was very small, so these measurements cannot be done with enough precision to be of any use other than as a guideline.

The differential effects on germination imply that the developmental processes of this stage can be unlinked, and that chemical inhibition may be used to identify specific developmental processes. However, chemical inhibition by those inhibitors tested does not seem to be suitable for use in studying vegetative growth and sporogenesis. The high levels of inhibitors needed would make it difficult to be certain that one was measuring a specific effect of the inhibitor and the lack of a differential effect on either vegetative growth or sporogenesis reduces the usefulness of these inhibitors. The increased concentration of inhibitor required may be due to a change in permeability during vegetative growth and sporogenesis.

The authors wish to thank Mrs Cathy Ditto for her technical assistance, Dr T. Seale and Mr David Rubin for their help with the photographs, and Dr S. Kaplan for his critical reading of this manuscript. This work was supported by grant number PHS GM I849I from the National Institute of General Medical Sciences to D.D.B. 


\section{REFERENCES}

Burke, D. D., Seale, T. W. \& McCarthy, B. J. (1972). Protein and ribonucleic acid synthesis during the diploid life cycle of Allomyces arbuscula. Journal of Bacteriology ro, 1065-1072.

EMERSON, R. \& WiLSON, C. (1954). Interspecific hybrids and the cytogenetics and cytotaxonomy of Euallomyces. Mycologia 46, 393-434.

GRIFFIN, D. H. \& BREUKER, C. (1969). Ribonucleic acid synthesis during the differentiation of sporangia in the water mold Achlya. Journal of Bacteriology 98, 689-696.

HAROLD, T. M. (1972). Conservation and transformation of energy by bacterial membranes. Bacteriological Reviews 36, I 72-229.

Kroon, A. M. \& DE VRIEs, H. (1970). Control of organelle development. In Society for Experimental Biology Symposium XXIV, pp. 18I-I99. New York: Academic.

LOVETT, J. S. (1963). Chemical and physical characterization of 'nuclear caps' isolated from Blastocladiella emersonii zoospores. Journal of Bacteriology 85, $1235-1246$.

LovetT, J. S. (1967). Aquatic fungi. In Methods in Developmental Biology, pp. 34I-358. Edited by F. H. Wilt and N. K. Wessels. New York: Thomas Y. Crowell.

LOVETT, J.S. (1968). Reactivation of ribonucleic acid and protein synthesis during germination of Blastocladiella zoospores and the role of the nuclear cap. Journal of Bacteriology 96, 962-969.

MACHLIs, L. (I953). Growth and nutrition of water molds in the subgenus Euallomyces. II. Optimal concentration of the minimal medium. American Journal of Botany 40, 456-460.

Machlis, L. \& CrasemanN, J. (1956). Physiological variation between the generations and among strains of water molds in the subgenus Euallomyces. American Journal of Botany 43, 60I-6I I.

Machlis, L., Mitting, W. H., Williams, N. W. \& Rapport, H. (I966). Production, isolation and characterization of sirenin. Biochemistry, New York 5, 2147-21 52.

Matsuma, A. \& Cantino, E. C. (1971). Sensitivity of the spores of Blastocladiella emersonii and related fungi to antibiotics and some other drugs. Journal of Antibiotics 24, 77-84.

MuRPHY, Sr, M. N. \& LOVETT, J. S. (I966). RNA and protein synthesis during zoospore differentiation in synchronized cultures of Blastocladiella. Developmental Biology 14, 68-95.

PESTKA, S. (197I). Inhibitors of ribosome functions. Annual Review of Biochemistry 40, 697-710. 